\title{
GMR
}

\section{Isolation and characterization of microsatellite loci in hybrid giant tiger grouper}

\author{
Y.S. Huang ${ }^{1,2}$, Z.B. Li ${ }^{1,2}$, Y.F. Ning ${ }^{1,2}$, J.B. Shangguan ${ }^{1,2}$, Y. Yuan ${ }^{1,2}$, \\ X.Q. $\mathrm{MaO}^{1,2}$ and B.B. $\mathrm{Li}^{1,2}$ \\ ${ }^{1}$ Fisheries College, Jimei University, Xiamen, China \\ ${ }^{2}$ Fujian Provincial Key Laboratory of Marine Fishery Resources and \\ Eco-Environment, Xiamen, China
}

Corresponding author: B.B. Li.

E-mail: lizhongbao@jmu.edu.cn

Genet. Mol. Res. 14 (4): 14706-14710 (2015)

Received June 14, 2015

Accepted September 15, 2015

Published November 18, 2015

DOI http://dx.doi.org/10.4238/2015.November.18.35

\begin{abstract}
The hybrid giant tiger grouper is a fish that has considerable commercial value and has become increasingly important for aquaculture in South East Asia since 2008. In order to prevent any reduction in genetic diversity in hybrid grouper as a result of aquaculture, we have identified 21 microsatellite markers that can be used to estimate genetic variation in the fish population. The number of alleles at polymorphic microsatellite loci ranged from 2 to 7 , and observed and expected heterozygosities varied from 0.0323 to 0.9643 and 0.0921 to 0.7174 , respectively. Polymorphism information content values ranged from 0.088 to 0.737 . Nineteen of the 21 loci were in Hardy-Weinberg equilibrium $(\mathrm{P}>0.005)$ after application of the Bonferroni correction $(\mathrm{k}=10)$, the exceptions being ZZLD35 ( $\mathrm{P}$ $<0.005)$ and ZZLD36 $(\mathrm{P}<0.001)$. No linkage disequilibrium was
\end{abstract}


detected. These 21 microsatellite markers are potentially of great value for analyzing genetic diversity to provide essential information for sustainable management of these fish.

Key words: Conservation; Genetic Diversity; Microsatellite; Hybrid giant Tiger grouper

\section{INTRODUCTION}

The hybrid giant tiger grouper is derived from the cross of male Epinephelus lanceolatus (considered vulnerable by the IUCN) and female Epinephelus fuscoguttatus (considered near threatened by the IUCN) (RBFHG, 2007). At present, Taiwan (China) and Malaysia are the main areas of production of this hybrid grouper. As the fish shows both disease resistance and rapid growth rates, it is of considerable commercial value and has become important in fish culture in South East Asia in recent years. However, the use of a fish such as the hybrid giant tiger grouper may be problematical if only economic aspects receive attention and protection is neglected. It is necessary to maintain its genetic diversity so that the fish can be produced commercially using sustainable development. Additionally, any program to monitor the genetic diversity must also consider the situation of the parental species to ensure successful breeding. In the present study, we sought to evaluate the genetic variation of the germplasm of hybrid giant tiger grouper through analysis of the genetic structure using microsatellite markers. The microsatellite technique has proven to be a valuable means for analyzing genetic diversity in breeding programs (Wolfus et al., 1997). To the best of our knowledge, this approach has not previously been applied to the hybrid giant tiger grouper. Here, we identified 21 microsatellite markers for this hybrid that can be used to examine genetic diversity. Through use of these markers, it should be possible to prevent the loss of rare germplasms and to promote genetic diversity within the farmed populations of hybrid grouper.

\section{MATERIAL AND METHODS}

The microsatellite loci were developed using the protocol for fast isolation of amplified fragment length polymorphisms in sequences containing repeats (Zane et al., 2002). Genomic DNA was extracted using a Genomic DNA Extraction kit (Tiangen, Beijing, China) and was digested with $M s e I$ (Thermo Scientific, Waltham, MA, USA) at $65^{\circ} \mathrm{C}$ for $10 \mathrm{~min}$. The digested fragments were ligated to $\mathrm{Mse}$ I adapter A (5'-ACGATGAGTCCT GAG-3')/MseI adapter B (5'-TACTCAGGACTCAT-3') by T4 DNA ligase at $37^{\circ} \mathrm{C}$ for 3.5 $\mathrm{h}$. The digestion-ligation mixture was then hybridized to the biotinylated probes $(\mathrm{CT})_{15}$ and $(\mathrm{GT})_{15}$ (Chen et al., 2012). DNA fragments containing microsatellite repeats were collected using Streptavidin MagneSphere ${ }^{\circledR}$ Paramagnetic Particles (Promega, Madison, WI, USA). The recovered DNA fragments were then amplified with the MseI A primer. PCR products were purified using GenCleanPCR (Generay Biotech, Shanghai, China) and ligated to PMD19-T (Takara, Shiga, Japan) at $16^{\circ} \mathrm{C}$ for $3.5 \mathrm{~h}$. The plasmids were 
transformed into Escherichia coli and transformants were selected on lysogeny broth agar plates that included ampicillin. Positive clones were confirmed by PCR amplification using the universal M13 primer. The PCR products were separated on 1\% agarose gels, and 215 positive clones ranging in size from 450 to $1000 \mathrm{bp}$ were selected and then sequenced by Invitrogen Company (Guangzhou, China). We then designed 49 pairs of primers using Primer Premier 5.0 based on the sequencing results.

All primer pairs were tested using gradient PCR at an annealing temperature range of $50^{\circ}$ to $60^{\circ} \mathrm{C}$ to identify the optimum annealing temperature. DNAs were obtained from a population of 31 hybrid giant tiger grouper collected from Xiamen, China, and used for the subsequent analyses. PCR was performed using $100 \mathrm{ng}$ template DNA, 1X EasyTaq Buffer for PAGE and 2.5 U EasyTaq DNA Polymerase for PAGE (TransGen Biotech, Beijing, China), $0.4 \mathrm{mM}$ dNTPs (Generay Biotech), and $0.4 \mu \mathrm{M}$ of each primer in a $10-\mu \mathrm{L}$ final volume with the amplification protocol: initial denaturation at $94^{\circ} \mathrm{C}$ for $5 \mathrm{~min} ; 35$ cycles at $94^{\circ} \mathrm{C}$ for $30 \mathrm{~s}, \mathrm{Ta}$ (primer optimal annealing temperature; Table 1) for $30 \mathrm{~s}, 72^{\circ} \mathrm{C}$ for $1 \mathrm{~min}$; and a final extension at $72^{\circ} \mathrm{C}$ for $10 \mathrm{~min}$. Polymorphic amplification products were separated on $6 \%$ denaturing polyacrylamide gels with Sequi-Gen Sequencing Cell (Bio-Rad, Hercules, CA, USA). The number of alleles per locus $\left(N_{\mathrm{A}}\right)$, observed $\left(H_{\mathrm{O}}\right)$ and expected $\left(H_{\mathrm{E}}\right)$ heterozygosities, and polymorphic information content (PIC) values were calculated using POPGEN32 (version 1.32) (Yeh et al., 2000) and CERVUS 3.0 (version 2.2.3) softwares. Deviation from the Hardy-Weinberg equilibrium and genotypic linkage disequilibrium were also tested utilizing POPGEN32 version 1.32 .

\section{RESULTS AND DISCUSSION}

Among the 49 loci tested, 10 were polymorphic with $N_{\mathrm{A}}$ ranging from 2 to $7, H_{\mathrm{O}}$ from 0.0323 to $0.9643, H_{\mathrm{E}}$ from 0.0921 to 0.7174 , and PIC values from 0.088 to 0.737 (Table 1). Eleven loci were monomorphic. The remaining loci were eliminated as they gave a vague outcome with abundant bands or else failed to provide amplification products. In this study, no linkage disequilibrium was detected after applying the Bonferroni correction $(\mathrm{k}=10)$. Eight of the 10 polymorphic loci were in Hardy-Weinberg equilibrium $(\mathrm{P}>$ 0.005); the exceptions were ZZLD35 $(\mathrm{P}<0.005)$ and ZZLD36 $(\mathrm{P}<0.001)$. The deviation from Hardy-Weinberg equilibrium is likely attributable to the small size of the sample as well as to the occurrence of null alleles (Pemberton et al., 1995; Li et al., 2006). The data on genetic diversity obtained here showed that hybrid giant tiger grouper has a medium PIC level, indicating that this population is not in a dangerous condition. Considering that these data provide a snapshot of genetic diversity at the beginning of the breeding of these fish, this finding is reassuring and acceptable.

In summary, 10 microsatellites markers from hybrid giant tiger grouper were developed, showed successful amplification and presented high levels of heterozygosis. These markers provide the basic materials for further study to analyze genetic diversity in these fish and will be of value for conservation of the germplasm, development of breeding strategies, and for sustainable management. We will monitor future progress in grouper aquaculture to gather more extensive data on the genetic structure of hybrid giant tiger grouper to ensure the protection of its genetic diversity and of the parental species. 


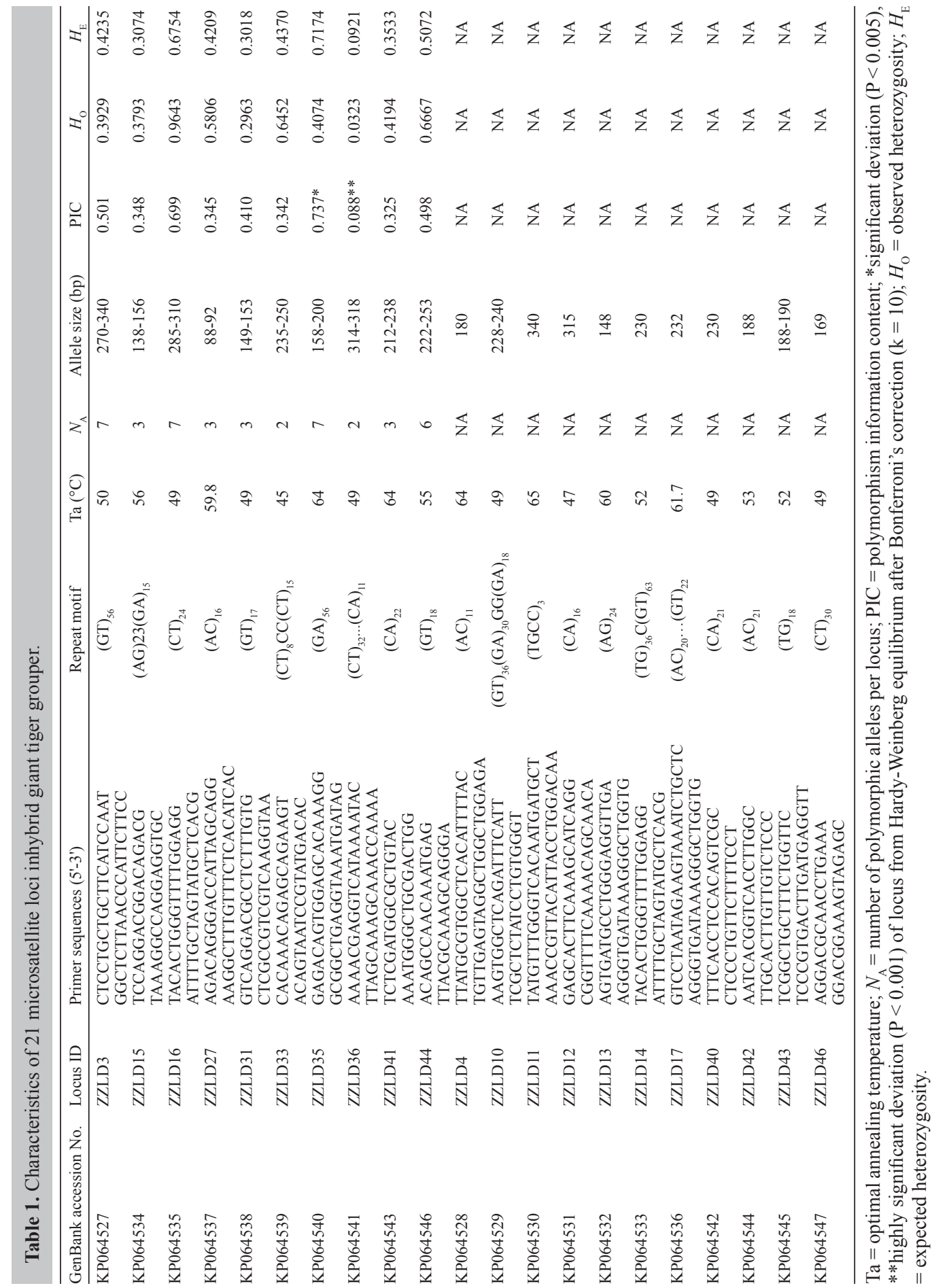




\section{Conflicts of interest}

The authors declare no conflict of interest.

\section{ACKNOWLEDGMENTS}

Research supported by the National Natural Science Foundation of China (\#31272668), the Foundation for Science and Technology Bureau of Xiamen (\#3502Z20153009); the Xiamen Southern Oceanographic Center (\#14CZY045HJ19), and the Foundation for Innovative Research Team of Jimei University, China (\#2010A004).

\section{REFERENCES}

Chen L, Li ZB, Chen XJ, Cao YY, et al. (2012). Isolation and characterization of 15 microsatellite loci in Acrossocheilus labiatus Regan (Cyprinidae). Conserv. Genet. Res. 4: 167-169.

Li ZB, Appleyard SA and Elliott NG (2006). Population structure of Haliotis rubra from South Australia inferred from nuclear and mtDNA analyses. Acta Oceanol. Sin. 25: 99-112.

Pemberton JM, Slate J, Bancroft DR and Barrett JA (1995). Nonamplifying alleles at microsatellite loci: a caution for parentage and population studies. Mol. Ecol. 4: 249-252.

RBFHG. Researchers Breed First Hybrid Grouper (2007). TheFishSite News Desk. Available at [http://www.thefishsite. com/fishnews/3629/researchers-breed-first-hybrid-grouper]. Accessed December 22, 2014.

Wolfus GM, Garcia DK and Alcivar-Warren A (1997). Application of the microsatellite technique for analyzing genetic diversity in shrimp breeding programs. Aquaculture 152: 35-47.

Yeh FC, Yang R, Boyle TJ, Ye Z, et al. (2000). PopGene32, Microsoft Windows-based freeware for population genetic analysis. Version 1.32, Molecular Biology and Biotechnology Centre. University of Alberta, Alberta.

Zane L, Bargelloni L and Patarnello T (2002). Strategies for microsatellite isolation: a review. Mol. Ecol. 11: 1-16. 